\title{
MANAGE THE COMPLEXITY OF ARCHITECTURAL DESIGN THROUGH THE PROACTIVE DESIGN PARADIGM
}

\author{
Gabriele Novembri ${ }^{1}$, Francesco Livio Rossini ${ }^{2}$, and Antonio Fioravanti ${ }^{3}$
}

\section{BaCkground And Identification of Problem / Knowledge GaP}

Nowadays, the building process shows a low success rate in terms of reliance of imposed time and cost forecasting. The causes are multiple: the lack of collaboration between the actors, the use of tools not suitable for managing the complexity of the contemporary building, the fragmentation of the market and an overall technological delay in production techniques, still linked to a "craft" vision of the building or anchored to a vision of the industrial system of the second or third industrial revolution. These are just some of the lacks affecting the construction chain which, since 2008, has been experiencing a continuous haemorrhage of revenues and personnel (Marchesini, 2016). In order to solve the numerous practical problems of design, architects, like all the process actors, iteratively seek appropriate solutions, which can be implemented according to the available resources (Roewe, 1987). In these conditions, it is essential to systematize information and knowledge about the building organization in a consistent manner, considering that, in the advancement of the various design phases, there may be different types, some due to its own peculiarities that lead to problems such as:

- those due to further design constraints may emerge during the design and construction phases;

- design problems that change because and their temporary solutions (partial or total) interact with the design objectives that change from the initial ones;

- those caused by the long duration of the useful life of the building organization, if compared to other manufacturing sectors, which lead to change the intended use, which are due to adaptation to changing regulations, emergency situations not predictable a priori, etc.;

Therefore, in order to stem the complexity and multiplicity of architectural design, since the earliest times the actors have created canons, styles and repeatable solutions (e.g.: the capitals of temples and the ashlars of Gothic cathedrals) to arrive, in the 20th century, at often ideological strategies (e.g. "form follows function") aimed at reducing such uncertainties and standardizing the approach to problem solving. Now, in the 'Post Industrial Digital Era' an attempt to bind architectural design into solutions where financial risks and technological uncertainties could be predictable (Wang and Crolla, 2018) is currently underway. However, these approaches have demonstrated over time all their limitations until, through the refinement of ICT techniques, digital tools and techniques have revealed the inconsistencies and limitations of this approach given the logical and methodological rigor, applied through algorithms, which did not allow any ambiguity. Subsequently, the construction sector was progressively enriched by new methodologies (e.g. CAD/CAM, BIM, etc.) capable of increasing the collaboration of processes, simplifying the verification cycles by all actors and, for the production of components, connecting the project directly to the machine (digital fabrication). But this transformation did not take place in parallel in the design and construction methodologies and in the process chain. The goal of the research is therefore the definition of a new collaborative design methodology, based on advanced digital modeling tools capable of supporting designers according to the simulative approach. In this way, it is possible to analyse in advance problems and results of design and construction in a virtual environment, avoiding the need to make up for design shortcomings with expensive variations during the work. To achieve this goal, the BIM modeling environment was linked to a simulation environment based on the Agents paradigm. These Agents, governed by their rules, behaviours and objectives, define their actions based on the ability to predict, thanks to the simulation, the results of their choices and, therefore, establish an overall rate of satisfaction of all due requirements.

\section{Research Aim And Methodology}

The aim of the System under development is to be a design assistant able to interface with the designer, putting to system - through the modeling of these aspects as autonomous interconnected agents - the current practice (eg: data

1 Assistant Professor, Sapienza - University of Rome, Department of Civil, Building and Environmental Engineering, Faculty of Civil and Industrial Engineering, Rome, ITA, gabriele.novembri@uniroma1.it.

2 Research Fellow, Sapienza - University of Rome, Department of Civil, Building and Environmental Engineering, Faculty of Civil and Industrial Engineering, Rome, ITA, francesco.rossini@uniroma1.it.

3 Assistant Professor, Sapienza - University of Rome, Department of Civil, Building and Environmental Engineering, Faculty of Civil and Industrial Engineering, Rome, ITA, antonio.fioravanti@uniroma1.it. 
from data sheets), cognitive psychology (standard solutions, designer's preferences, conventions, etc..) and computational intelligence, understood in this case as the ability to have such computing power as to be able to launch many simulations on the same phenomenon, analyse and infer on a wider spectrum of cases and increase the accuracy of the final result. In concrete terms, the system is based on the concept of an 'Autonomous Agent', that is an entity capable of carrying out operations according to internal and external conditions, attributes, topology, behavioural rules and set objectives, without direct human control (Wooldridge, 2009). This independence can be declined according to different levels of complexity: In fact, an agent can have very simple behaviours, purely reactive with respect to the application of conditional rules of 'if-then' (PR Predicate Rules), or present ever greater levels of intelligence such as, for example, the behaviour based on the application of rules in an ' event based' relation or from the history of the process (data driven, narrative), until reaching complete autonomy (Castelfranchi and Falcone, 1998) which, also thanks to systems of statistical inference, lead to pro-active behaviour, that is, the condition in which the machine - in addition to prefiguring the outcome of the choices - suggests one or more solutions capable of achieving the best result in relation to the needs to be satisfied. Moreover, the agent has a purely relational nature, aimed at creating multiagent systems, which are better suited to modeling complex reality and its dynamic interconnections. The prototype was developed to link the results of the iterations that took place in the high intelligence simulative environment (Novembri et al., 2017) Agent-based with the BIM world, using the connection made available by the API (Application Programming Interface), thus creating a continuous, reciprocal, updating of the data of the two levels. Therefore, each BIM object (both instance and prototype) will be replicated in the higher intelligence abstraction level through an "agent system" according to its own rules, objectives and behaviours. Taking as an example a building, this will be modeled in the system through an agent who must achieve objectives, to the extent that the other agents will also have to satisfy theirs. This process works in parallel on BIM objects. It ends when each BIM object has found, satisfying the requirements imposed, its size and characteristics in relation to others.

\section{RESEARCH FINDINGS}

The results, limited to the example elaborated for the purpose, is the automatic generation of a building detail (building component, procedure, work area, etc.) such as to satisfy all the macro and micro frameworks of the agents involved in where, among other properties, the workers to be employed and the areas to be occupied are inserted, in such a way as to be able to verify also the aspects related to the constructability of the building. The result of this interaction takes place through a graphic interface called 'canvas' that describes, given the executive design of the elements contained in that area, the timing and the actual work area, also taking into account the propaedeutic sequence between the various activities. This Agent System prototype aims to be a design partner, able to dialogue with the actor-designer, first of all imitating the approach modes such as, for example, the ability to think according to different levels of abstraction of intelligence and taking into account the different design solutions, albeit partial. Moreover, the usefulness of this approach is given by the dynamic behaviour of multi-agent systems which, when stimulated, activate the entire respective network of interdependencies in order to elaborate as many solutions as possible necessary to define the "satisfycing" state to be reached (Simon, 1996). Moreover, in addition to the possibilities given by the combination of statistical intelligence and computer science of inferential logic, there are also the techniques of artificial neural networks, genetic algorithms and Fuzzy simulations to be deeply tested. The perspectives of this research are in the interconnection of systems with agents with advanced sensors, according to the paradigm IoT Internet of Things). In this way, the Agent will be put in constant communication with the real environment, opening up new paths such as: the constant collection of data on existing structures, the optimization of frequency and maintenance interventions, the micro-robotics of the site.

\section{REFERENCES}

Carrara G, Fioravanti A (2007) X-House - a Game to Improve Collaboration, in Predicting the Future, proceedings of the 25th eCAADe Conference, Frankfurt am Main, Germany, pp.141-149.

Castelfranchi C., Falcone R., (1998) Toward a theory of delegation for Agents-Based systems. Robotics and Autonomous systems, 24: 141-157.

Marchesini E (2016) Nel 2020 le costruzioni varranno il 15\% del PIL. Il Sole 24 Ore , 15/09/2011. (http://quiimpresa.ilsole24ore.com/autodesk/architettura-edilizia/costruzioni-nel-2020_PRN.php).

Rowe P G (1987) Design Thinking, MA MIT Press, Cambridge.

Simon HA (1996) The Sciences of the Artificial, 3rd Edition, MIT Press, Cambridge, MA, USA.

Wang S, Crolla K (2018) Design Practice complexity in the post digital age. Theoretical discussion and comparative case study of non-standard building façades. In Proceedings of the 24th annual conference of the association for computer-aided architectural design research in Asia - CAADRIA 2019, Wellington, AUS, pp. 481-490.

Wooldridge, M. (2009) An introduction to Multi-Agent systems. John Wiley \& Sons, 2008, pp. 325-336. 